\title{
TRACKING THE GROWING RINGS IN BIOGENIC ARAGONITE FROM FISH OTOLITH USING CONFOCAL RAMAN MICROSPECTROSCOPY AND IMAGING
}

\author{
GEZA LAZAR $^{a}$, CALIN FIRTA $^{\mathrm{a}, \mathrm{b}}$, SANJA MATIĆ-SKOKO ${ }^{c}$, \\ MELITA PEHARDAc, DARIO VRDOLJAK ${ }^{c}$, HANA UVANOVIĆc, \\ FRAN NEKVAPIL ${ }^{\mathrm{a}, \mathrm{b}}$, BRANKO GLAMUZINA ${ }^{\mathrm{d}}$, \\ SIMONA CINTA PINZARU ${ }^{*}$
}

\begin{abstract}
Fish otoliths pose increasing interest due to their potential of rendering information about environmental changes, underlined in their non-linear time-dependent biogenic crystal growth. Otoliths are acellular, metabolically inert and continuously grow in a complex process which still needs to be understood. In the present work confocal Raman microspectroscopy (CRM) and imaging is employed to investigate the growth pattern in otoliths from Sparus aurata of Mediterranean provenance. CRM signal acquired from otolith sagittal section is exploited to associate it with the periodic growth increments denoted as rings. Raman signal collected from the core to the margins with micrometer spatial resolution invariably revealed characteristic signal of aragonite. Relative intensity variability was observed particularly for the lattice modes, indicating changes in crystalline orientation relative to incident laser. Bands associated with organic fraction were absent in the $90-1840 \mathrm{~cm}^{-1}$ spectral range. Daily growth rings were further studied using the Raman mapping of main aragonite bands intensities at 1083,704 and the lattice modes in the $100-350 \mathrm{~cm}^{-1}$ range. The spectral intensity pattern closely follows the daily growth pattern. Traces of toxic or heavy metals incorporated in biogenic carbonate mineral were spuriously detected in the mapped areas, according to the position and width of the Raman bands of witherite $\left(\mathrm{BaCO}_{3}\right)$, strontianite $\left(\mathrm{SrCO}_{3}\right)$, along with the main aragonite and trace of its calcite polymorph.
\end{abstract}

Keywords: Confocal Raman micro-spectroscopy, fish otoliths, Raman mapping, growth rings, aragonite.

a Babes-Bolyai University, Biomolecular Physics Department, Kogalniceanu 1, RO-400084 ClujNapoca, Romania

b National Institute for Research and Development of Isotopic and Molecular Technologies, 400293 Cluj-Napoca, Romania

c Institute of Oceanography and Fisheries, Šetalište I. Meštrovića 63, 21000 Split, Croatia

d University of Dubrovnik, Department for Aquaculture, Cira Carića 4, 20000 Dubrovnik, Croatia

* Corresponding author simona.cinta@phys.ubbcluj.ro 
GEZA LAZAR, CALIN FIRTA, SANJA MATIĆ-SKOKO, MELITA PEHARDA, DARIO VRDOLJAK, HANA UVANOVIĆ, FRAN NEKVAPIL, BRANKO GLAMUZINA, SIMONA CINTA PINZARU

\section{INTRODUCTION}

Otoliths are crystalline $\mathrm{CaCO}_{3}$ biominerals with a small fraction of organic matrix, located in the inner ear of vertebrates. They serve as a balance organ for equilibrium and contribute to hearing [1], [2]. Fish otoliths are increasingly investigated due to the potential correlation of their lifetime development with the environmental changes they encountered. Defined as opaque zones delimiting the translucent ones, the otoliths growing rings provide valuable tool for the fish age determination. The use of otoliths as chronometric structures to track the recorded environmental conditions along the organism life-time is still in its infancy. However, increasing number of Raman spectroscopy studies already refer to the otolith sclerochronology as valuable tools for tracking environmental changes [3-4], employing the characteristic Raman signature of calcium carbonate polymorphs [5] which could occur in otoliths complex biomineralization process. Their growth pattern is composed of a number of concentric rings with different radii. Depending on the amount of organic material in each shell or zone, its appearance will vary from extremely opaque to complete hyaline (transparent) with the first zone being the nucleus (core) of the otolith. These zones are also called growth rings [4]. Previous Raman studies showed that the characteristic polymorph of calcium carbonate biomatrix, present in otoliths, is aragonite with the typical Raman vibration modes $v_{1}\left(1085 \mathrm{~cm}^{-1}\right)$ and $v_{4}\left(701 \mathrm{~cm}^{-1}\right.$ and $\left.705 \mathrm{~cm}^{-1}\right)$ as well as lattice modes ( 8 bands between $142 \mathrm{~cm}^{-1}$ and $282 \mathrm{~cm}^{-1}$ ) [3, 6]. Moreover, some studies have reported two different $\mathrm{CaCO}_{3}$ crystalline structures, aragonite and vaterite, in the otoliths of different fish species [7] [8] [9], which can differ dramatically in their trace elemental composition $[10,11]$. Some of the studies reported the coexistence of three polymorphs of calcium carbonate (calcite, aragonite, vaterite) in the shell of Antarctic bivalves having the same growing pattern (rings) as fish otoliths [12]. Gauldie et al (1997) [13] reported first vaterite polymorph signature in the low wavenumber range of the micro-Raman spectra of otoliths core from the coho salmon Oncorhynchus kisutch (Teleostei: Salmonidae) and highlighted the aragonite nature of the otolith first ring.

On the other hand, the polymorphs of calcium carbonate may interfere with other, mixed carbonate minerals, whose Raman analysis relies on correct interpretation of the specific lattice modes [14, 15]. Furthermore, strict similarity of the biogenic with geogenic mineral Raman feature must be treated with caution, since their environment and mechanism of formation is different. Wehrmeister et al (2010) showed that the structure of vaterite contains three crystallographic independent carbonate groups and similar carbonate group layers, and firstly assigned a band at $263 \mathrm{~cm}^{-1}$ to vaterite [16]. 
The aim of the current study is to probe the potential of the confocal Raman micro-spectroscopy (CRM) technique for detailed investigation of otolith morphology and growing pattern in Mediterranean Sparus aurata and to probe the versatility of the Raman technique to upscale the study for larger otoliths groups. Optimized conditions for screening would generate robust Raman data which could be further exploited for any correlation with environmental conditions encountered during fish otoliths lifetime period.

\section{RESULTS AND DISCUSSIONS}

From the larger set of otoliths, we randomly selected one as subject for the present detailed study, as a prerequisite for the forthcoming comparative Raman analyses of otolith sets. The investigated otolith fragment is shown in the Figure 1 along with the optical micrographs taken with the Raman microscope in transmission (b) and direct illumination (c) using a 20x objective (NA 0.35).
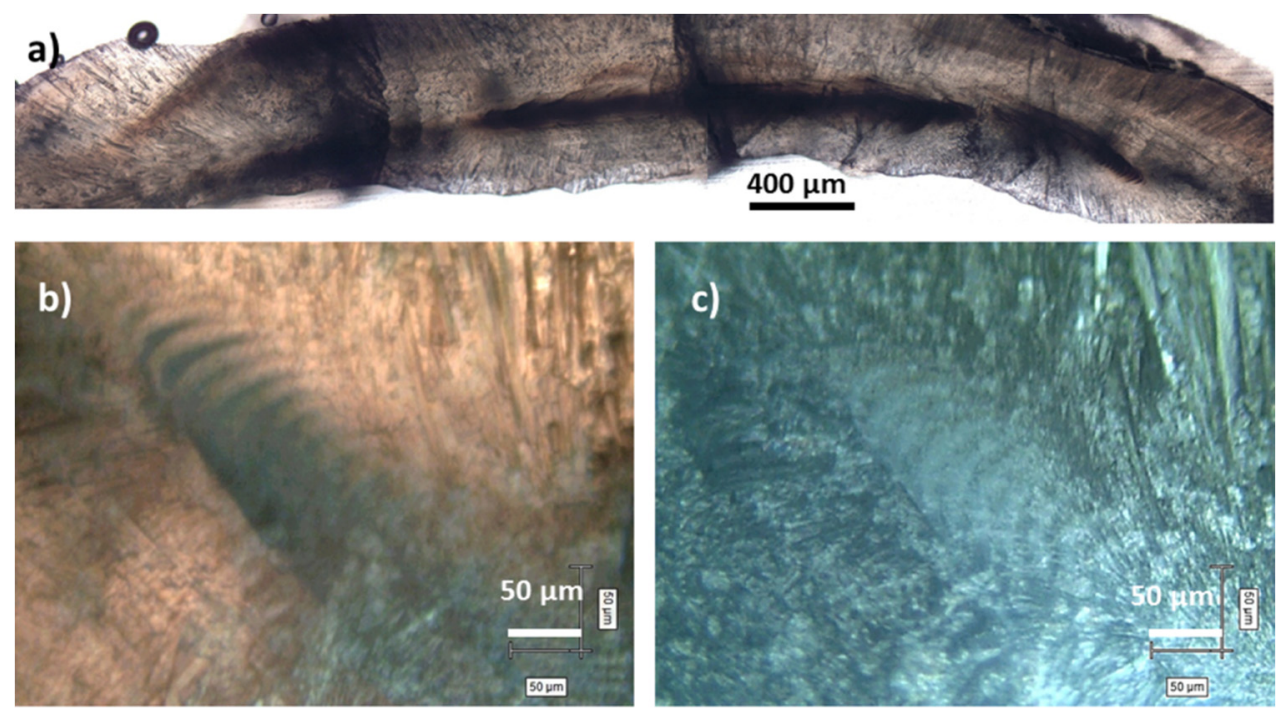

Figure 1. Photo-stitch of the otolith fragment in sagittal section (a), together with the light microscopy images taken with the Raman microscope in transmission (b) or direct illumination (c), using a 20x objective. Scale bars: $400 \mu \mathrm{m}$ (a) and $50 \mu \mathrm{m}$ (b and $c)$.

A series of CRM spectra presented in the Fig. 2 acquired from otolith along a line starting from core toward edge, with a $50 \mu \mathrm{m}$ step and corresponding to the growing direction, indicated by the orientation of the 
micro-crystallites, clearly depict aragonite as the main mineral component of the otolith across its sagittal section. These spectra were collected using the lowest magnification objective available (5x, NA 0.12). We noted lower background of the recorded signal when higher magnification objectives are employed. However, for gross screening of the whole otolith while preserving the screening line direction, the $5 x$ objective was optimal. Bearing in mind that high background in the Raman spectra could potentially masque additional, low intensity bands from other trace minerals, further analysis is devoted later.

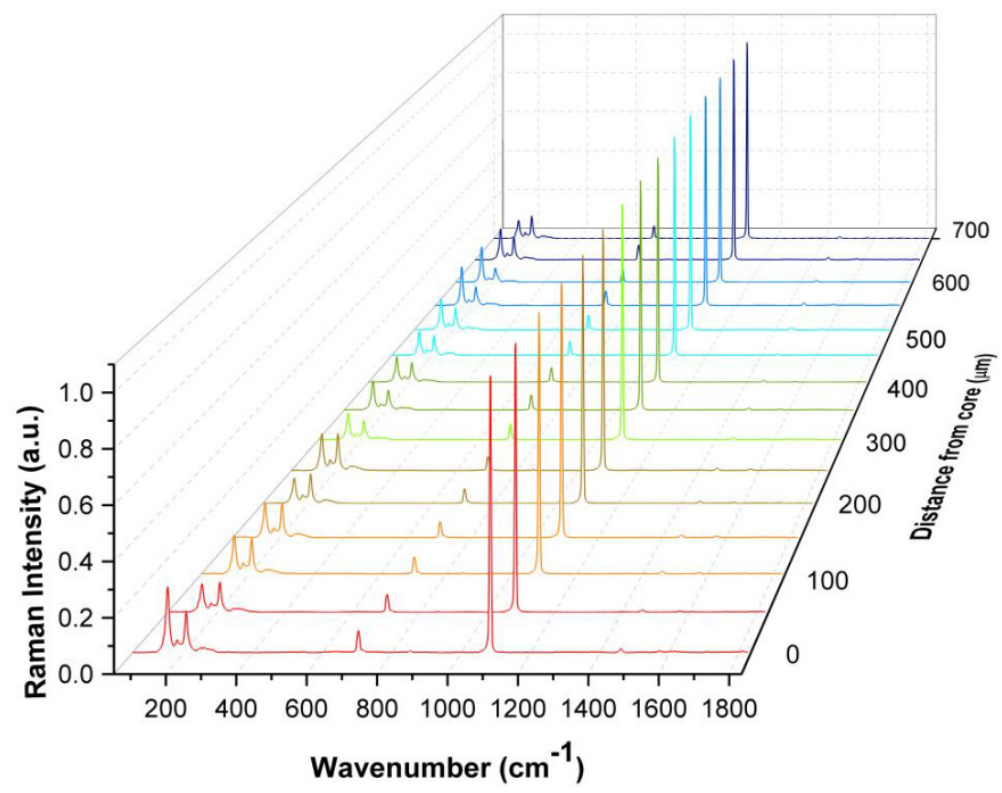

Figure 2. 3D display of the normalized, background subtracted CRM spectra collected along a line direction starting from otolith core toward edge with a $50 \mu \mathrm{m}$ step. Excitation: $532 \mathrm{~nm}, 5 \mathrm{x}$ objective (NA 0.12).

In geogenic aragonite, the unit cell of crystalline orthorhombic aragonite comprises 20 atoms (four fomula units in a crystalline cell). Its 57 vibrational modes are classified [19] according to the irreducible representations of point groups theory, as follows:

$$
\Gamma_{\text {total }}=9 A_{g}+6 A_{u}+6 B_{1 g}+8 B_{1 u}+9 B_{2 g}+5 B_{2 u}+6 B_{3 g}+8 B_{3 u} .
$$

The $\mathrm{g}$ (gerade) modes are all Raman active while $\mathrm{u}$ (ungerade) modes are IR active, with the exception of Au modes, which are silent [19]. Thus, Raman spectrum of aragonite is expected to show 30 fundamental modes. However, due to the fact that many of the vibrational modes are of very weak intensity, it is 
extremely difficult to detect experimentally all the active modes [19], particularly in natural samples. In synthetic aragonite [13] the lattice modes detected in Raman spectra were reported at 113 (w), 142 (s), 153 (s), 180 (w),190(w), 206 (m), $242(\mathrm{w}), 261(\mathrm{w}), 284 \mathrm{~cm}^{-1}(\mathrm{w})$, the symmetric stretching mode $v_{1}$ at $1085 \mathrm{~cm}^{-1}$ (vs), the $v_{3}$ at $1462(\mathrm{w})$ and $1574(\mathrm{w})$ and the $v_{4}$ at $701(\mathrm{~s})$ and $705 \mathrm{~cm}^{-1}(\mathrm{~m})$. Table 1 summarized the observed Raman bands in otolith core and first ring, in comparison with the reported Raman data of geogenic aragonite $[18,19]$ calcite [19], vaterite [17] and two other minerals from the aragonite group, witherite [14] and strontianite [17], along with their assignment.

Table1. The Raman bands observed in spectra collected from otolith core and first ring along with the characteristic bands of geogenic aragonite polymorphs (calcite, vaterite) and other carbonate minerals from aragonite group, witherite, $\left(\mathrm{BaCO}_{3}\right)$ or strontianite $\left(\mathrm{SrCO}_{3}\right)$

\begin{tabular}{|c|c|c|c|c|c|c|c|c|}
\hline $\begin{array}{l}\text { Otolith } \\
\text { Core }\end{array}$ & $\begin{array}{l}\text { Otolith } \\
1^{\text {st }} \text { ring }\end{array}$ & $\begin{array}{c}\text { Aragonite } \\
\text { [19] }\end{array}$ & $\begin{array}{c}\text { Aragonite } \\
{[18]}\end{array}$ & $\begin{array}{c}\text { Calcite } \\
\text { [19] }\end{array}$ & $\begin{array}{c}\text { Vaterite } \\
\text { [17] }\end{array}$ & $\begin{array}{c}\text { Whiterite } \\
\text { [14] }\end{array}$ & $\begin{array}{c}\text { Stronitianite } \\
{[17]}\end{array}$ & \begin{tabular}{|c}
$\begin{array}{c}\text { Assignment } \\
\text { (Symmetry) } \\
{[19]}\end{array}$ \\
\end{tabular} \\
\hline 1461 & $\begin{array}{l}1457 \\
1571 \\
\end{array}$ & $\begin{array}{l}1462.2 \\
1573.9 \\
\end{array}$ & $\begin{array}{l}1463 \\
1576 \\
\end{array}$ & 1435.8 & & 1420 & 1445 & $v_{3}\left(B_{1 g}\right)$ \\
\hline 1083 & 1081 & 1085.3 & 1085 & 1086.2 & $\begin{array}{l}1080 \\
1090 \\
\end{array}$ & 1059 & 1071 & $v_{1}\left(A_{1 g}\right)$ \\
\hline & & 853.3 & 853 & & & & & $v_{2}\left(A_{g}\right)$ \\
\hline 685 & & & & \multirow{7}{*}{712.4} & \multirow{7}{*}{$\begin{array}{l}739 \\
749\end{array}$} & \multirow{7}{*}{$\begin{array}{l}690 \\
699\end{array}$} & \multirow{7}{*}{$\begin{array}{l}510 \\
710\end{array}$} & \multirow{7}{*}{$\begin{array}{l}v_{4}\left(A_{g}\right) \\
\left(B_{2 g}\right)\end{array}$} \\
\hline 690 & & & & & & & & \\
\hline 699 & 700 & 701.8 & 701 & & & & & \\
\hline 704 & 704 & 706.1 & 705 & & & & & \\
\hline 716 & 714 & 717.1 & 716 & & & & & \\
\hline 727 & & & & & & & & \\
\hline 731 & & & & & & & & \\
\hline & & 113.5 & 115 & \multirow{14}{*}{$\begin{array}{l}154.9 \\
281.2\end{array}$} & \multirow{14}{*}{$\begin{array}{l}106 \\
206 \\
265 \\
299\end{array}$} & \multirow{14}{*}{$\begin{array}{c}100 \\
135 \\
153 \\
179.67 \\
224.9\end{array}$} & \multirow{14}{*}{$\begin{array}{l}148 \\
180 \\
214 \\
236\end{array}$} & \multirow{14}{*}{$\begin{array}{l}\text { Lattice } \\
\text { Modes }\end{array}$} \\
\hline & & 125 & 125 & & & & & \\
\hline & & 142.9 & 145 & & & & & \\
\hline 152 & 153 & 153 & 155 & & & & & \\
\hline & & 162.2 & 164 & & & & & \\
\hline 180 & 180 & 180 & 182 & & & & & \\
\hline & & 190.7 & 192 & & & & & \\
\hline \multirow[t]{7}{*}{206} & 206 & 206.3 & 208 & & & & & \\
\hline & & 214.7 & 216 & & & & & \\
\hline & & 225.5 & & & & & & \\
\hline & 247 & 248.3 & 250 & & & & & \\
\hline & 260 & 260.1 & 263 & & & & & \\
\hline & & 272 & 274 & & & & & \\
\hline & & 283.6 & 285 & & & & & \\
\hline
\end{tabular}


The strong aragonite signal in the otolith (Fig. 2) was identified by the presence of the symmetric stretching mode of the carbonate $v_{1}$ at $1083 \mathrm{~cm}^{-1}$ and the $v_{4}$ vibrational mode at 701 and $704 \mathrm{~cm}^{-1}$ as well as lattice modes in the low wavenumbers region: 152, 180 and $206 \mathrm{~cm}^{-1}$. The aragonite signal has proved to be the strongest along the entire scan line with apparent traces [14] of other calcium carbonate polymorphs, while the organic matrix was not detectable using the 5x objective (NA 0.12 ) for excitation and collecting optics in $1 \mathrm{~s}$ acquisition.

Taking a closer microscopy look while taking Raman spectra with higher magnification objectives, such as $20 x$ (NA 0.35) or 100x (NA 0.9), respectively, subtle details have been observed on much lower background. The spectral details as showed in the Figure 3. Micro-Raman spectra collected from the first ring of otolith using three different objectives, 5x, 20x and 100x respectively, are showed in the Fig. 3 a) in comparison with the Raman spectra from RRUFF database of geogenic aragonite (RRUFF ID: R080142), calcite (RRUFF ID: R150075) and strontianite (RRUFF ID: R040037). Their spectra showed subtle differences, particularly in the lattice modes range $\left(50-300 \mathrm{~cm}^{-1}\right)$, and in the main stretching modes around 1083 and $704 \mathrm{~cm}^{-1}$. Spectral details are highlighted in the Fig. $3 \mathrm{~b}, \mathrm{c}$ and d, which allowed us to argue that trace of calcite, witherite and strontianite could be present [14]. In addition, the main Raman stretching mode at $1083 \mathrm{~cm}^{-1}$, which is slightly shifted from those of geogenic aragonite observed at $1085 \mathrm{~cm}^{-1}$, showed a narrower band for the otolith core than for the first ring. The shoulder at $1077 \mathrm{~cm}^{-1}$ (Fig. $3 \mathrm{~b}$ ) slightly higher in spectrum from the first ring than that from the core, and further different from that of geogenic aragonite, may suggest the presence of other carbonate mineral, such as strontianite (amorphous calcium carbonate was excluded, due to the clear evidence of the lattice modes). Zoom of the $680-740 \mathrm{~cm}^{-1}$ spectral range (Fig. $3 \mathrm{~d}$ ) revealed aragonite modes at $704 \mathrm{~cm}^{-1}$ with additional weak band (shoulder) at $700 \mathrm{~cm}^{-1}$, and other weak bands, potentially indicating calcite and witherite traces [14]. In the lattice modes region (Fig. $3 \mathrm{c}$ ) subtle differences among biogenic and geogenic aragonite are observed; the band at $180 \mathrm{~cm}^{-1}$ could be attributed to either aragonite or to a certain mixture of different carbonates [14]. Strontianite $(\mathrm{Sr} 0.91 \mathrm{Ca} 0.09) \mathrm{CO}_{3}$ exhibited main Raman band at $1077 \mathrm{~cm}^{-1}$ while in the lattice modes range it shows bands at 150 (strong) and $183 \mathrm{~cm}^{-1}$ (weak) which are overlapped with the aragonite lattice modes. Therefore, in an aragonite crystalline matrix, trace of $\mathrm{Sr}$ to replace Ca ions is difficult to reveal via Raman spectroscopy although the shoulder at $1077 \mathrm{~cm}^{-1}$ may suggest strontianite trace presence. Moreover, the $699 \mathrm{~cm}^{-1}$ mode of witherite [14] or strontianite [15] could be responsible for the observed shoulder in the $v_{4}$ Raman mode of aragonite centered at $704 \mathrm{~cm}^{-1}$ (Fig. 3). 
TRACKING THE GROWING RINGS IN BIOGENIC ARAGONITE FROM FISH OTOLITH USING CONFOCAL RAMAN MICROSPECTROSCOPY AND IMAGING
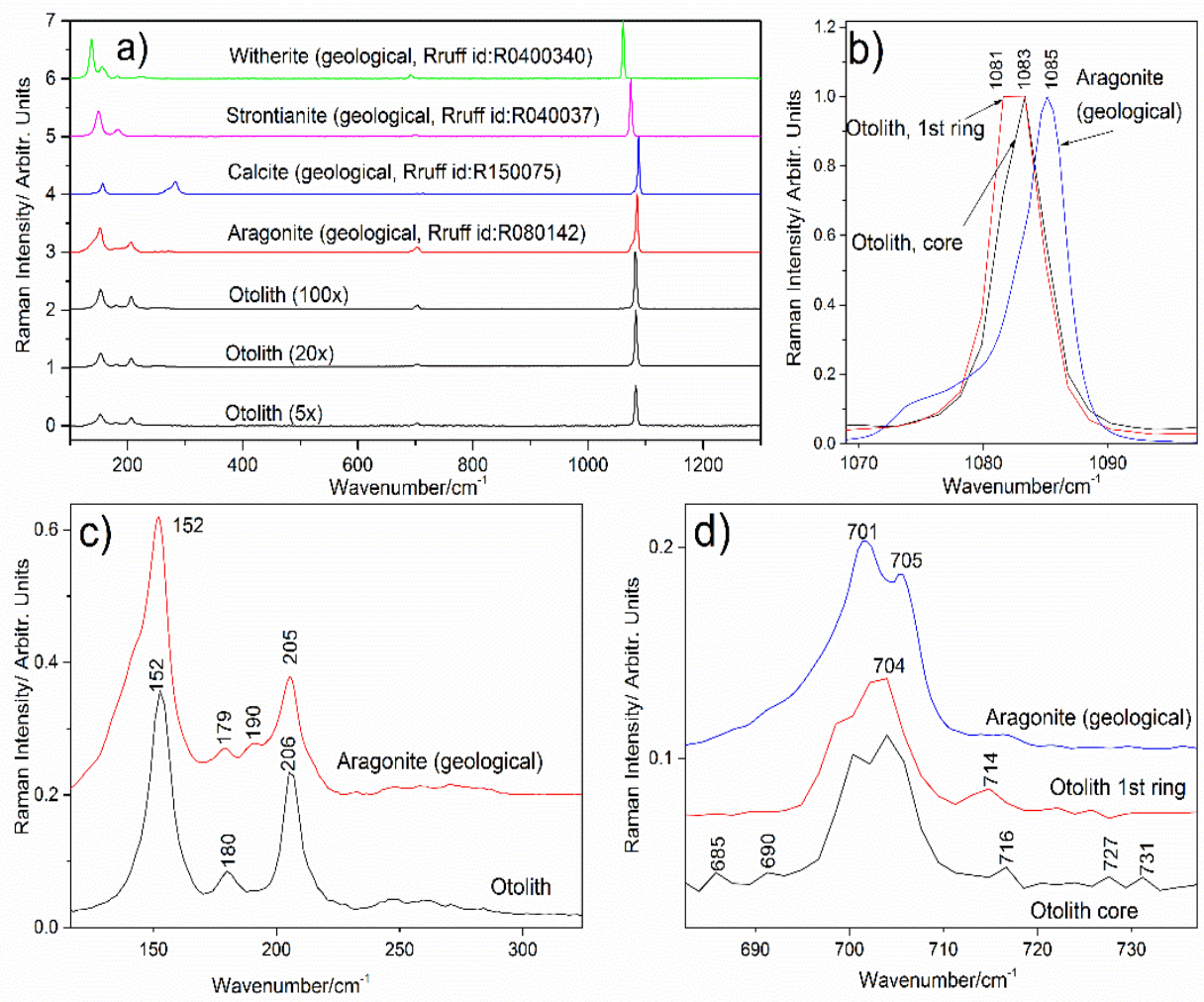

Figure 3. Micro-Raman spectra collected from the otolith in the optical region of the first yearly ring, using three different objectives, as indicated (a), in comparison with the geological aragonite (red, RRUFF ID: R080142), calcite (blue, RRUFF ID: R150075), strontianite (magenta, RRUFF ID: R040037) and witherite (green, RRUFF ID: 040040); (b) zoom of the main stretching mode at $1083 \mathrm{~cm}^{-1}$ showing narrower band for the otolith core than for the first ring; (c) lattice modes highlighting subtle differences among Raman signal of biogenic and geologic aragonite; (d) spectral zoom of the characteristic mode of aragonite at $704 \mathrm{~cm}^{-1}$ with additional weak bands potentially indicating calcite / strontianite trace; Excitation: $532 \mathrm{~nm}$. Otolith spectra from (b, c, d) are collected with 20x objective.

The presence of a weak band at $690 \mathrm{~cm}^{-1}$ suggests the presence of barium carbonate (witherite) [14]. The supposition is further sustained by the preliminary scanning electron microscopy and energy dispersive X-Ray analyses (SEMEDX) preliminary data (not shown here) on the otoliths set (manuscript in preparation), although the $\mathrm{Sr}$ trace randomly appeared at $0.2 \mathrm{Wt} \%$, thus, at the 
limit of EDX detection. The Raman spectra obtained with higher magnification objectives, describes a smaller area with better focus on the otolith saggital section surface and the presence of the new bands could be attributed to different crystal orientations or to the trace presence of other carbonates in that spot. Potential accumulation of heavy or toxic metals from environment at a certain moment of the fish otolith evolution is random and could result in random deposit of carbonate mineral with replaced calcium by the respective metal. Powdering the whole otolith for X-ray powder difraction (XRPD) would be an alternative solution for analysis, provided that the trace metal form other carbonate minerals is sufficient for the XRPD detection limit. The drawback of such analysis is the complete loss of the spatial location to track the moment (or ring age) the event occurred during the fish lifetime. Another isssue related to the fish age and the counting rings is connected to the non-linear growth and development of the otolith, where plethora of factors can compete.

Choosing appropriate optics, vaterite trace could be presumably detected according to the weak bands observed at $263 \mathrm{~cm}^{-1}$ [16], although the main vaterite bands at $740-750 \mathrm{~cm}^{-1}$ as well as the split of the main $v_{1}$ mode of carbonate is rather expected for typical vaterite polymorph presence. However, the major bands of vaterite were absent in the recorded spectra, sugesting its absence or trace occurence (vaterite being a metastable polymorph of calcium carbonate) compared to other dminant minerals. Also, the presence of other cations may promote the formation of the aragonite crystals. [17]

The daily rings or increments have been Raman mapped following the fast streamline imaging and signal-to-baseline criteria of the Wire 3.4 software. An area of $260 \mu \mathrm{m} \times 96 \mu \mathrm{m}$ has been selected over the light microscopy image of the otolith viewed with the $20 x$ objective. A scan step of $4 \mu \mathrm{m}$ was used, resulting 65x24 pixels with distinct spectral information from 1560 spectra. For map analysis, signal-to-baseline criteria for representative modes of aragonite (696-707 $\left.\mathrm{cm}^{-1}, 240-265 \mathrm{~cm}^{-1}\right)$, calcite $\left(279-285,712-716 \mathrm{~cm}^{-1}\right)$, strontianite (1073-1079 $\left.\mathrm{cm}^{-1}\right)$ distribution have been selected. Further, overlay maps were generated.

Examination of the mapping results (Fig. 4) in terms of Raman intensity distribution over the selected area provides an overview of the chemical and crystalline composition. The intensity distribution over the mapped area showed consistent feature supporting aragonite main component but trace of calcite and strontianite could be detected. Mapping over the main Raman mode at $1083 \mathrm{~cm}^{-1}$ resembled similar distribution feature. The fact that the growth rings are visible both in optical microscopy images and in Raman maps is a clear sign that the Raman signal intensity is strongly correlated to certain activity patterns of the daily rings fish development. The maps clearly show an alternation of minima and maxima in all cases which can be linked to the activity of the 

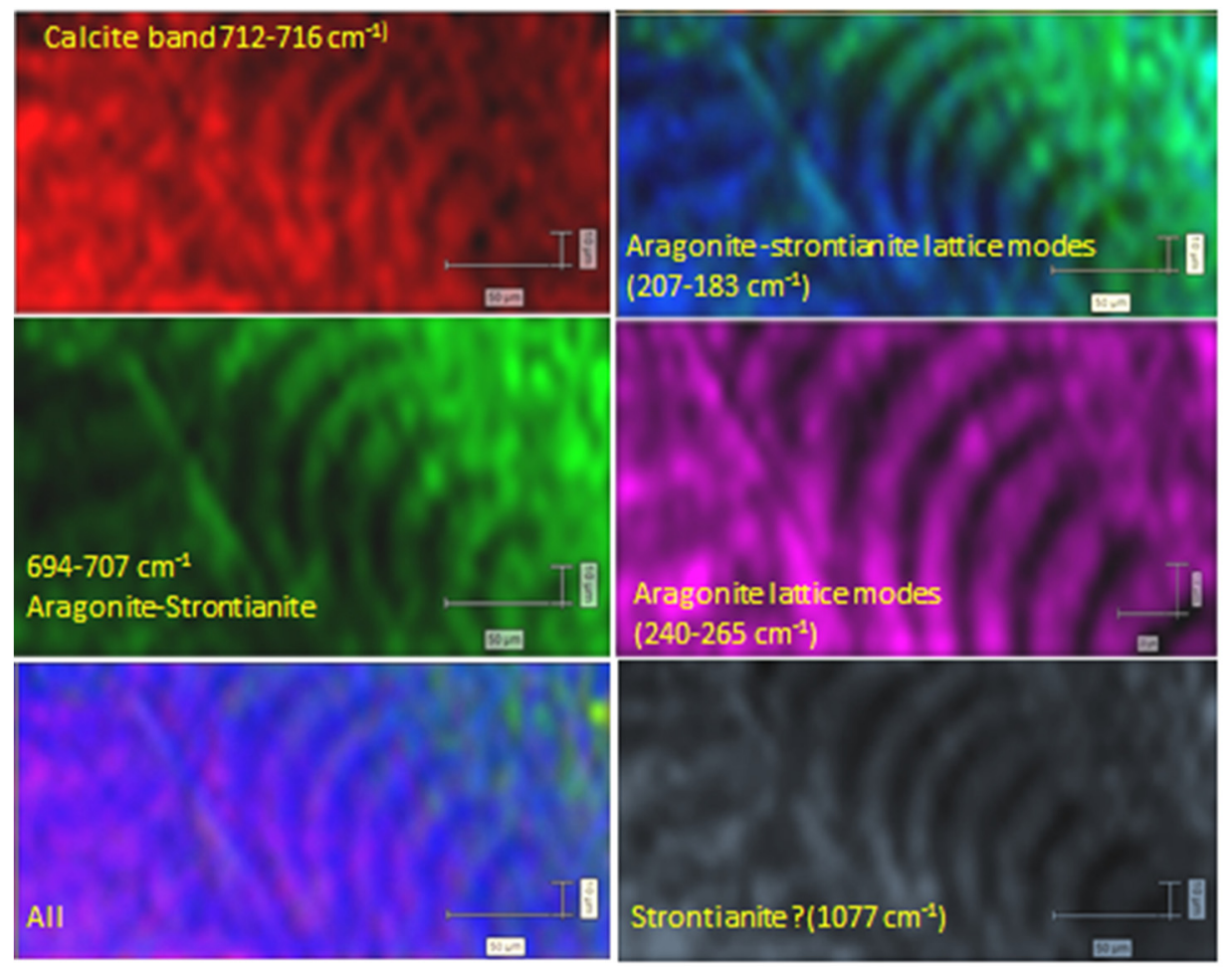

Figure 4. Raman mapping of otolith increments or "daily rings" following the signal-to-baseline criteria, as indicated in each map for trace of calcite (weak band between $712-716 \mathrm{~cm}^{-1}$, top left), aragonite-strontianite (lattice modes - top right), V4 mode - midde left), aragonite lattice modes (middle, right), trace of strontianite (1077 $\mathrm{cm}^{-1}$ bottom right) and all the overlapped images (bottom left).

fish on a daily cycle. The Raman intensity variation patterns follows the opacity patterns from light microscopy. The more intense color zones represeting areas with highest signal-to-baseline, suggest more deposited, highly ordered crystalline material and dark zones areas with less crystalline deposited material. This feature clearly suggests non-uniform otolith crystal growth which may be due to the genetic factors, water chemistry, temperature, migration habits, depth, and other variable conditions occuring in fish environment. Otolith spectroscopic data and their correlation in fish populations still needs to be understood. For such approaches, Raman versatility seems to be optimal for fast tracking information on the otolith gowth patterns. 
GEZA LAZAR, CALIN FIRTA, SANJA MATIĆ-SKOKO, MELITA PEHARDA, DARIO VRDOLJAK, HANA UVANOVIĆ, FRAN NEKVAPIL, BRANKO GLAMUZINA, SIMONA CINTA PINZARU

\section{CONCLUSIONS AND OUTLOOK}

The current study provides additional insight into the Raman spectroscopy of otoliths and the dependencies of the Raman spectral features on the selected optics for otolith screening. Confocal Raman micro-spectroscopy is suitable for tracking the otoliths development and potential heavy or toxic metals intake in chemical composition. Thus, Raman techniques proved to be important tools for tracing biomineralization. An integrated, larger study on otolith sets from similar species and habit could use the present results for comparative Raman analysis. For long term, we aim to probe the correlation of otolith morphology and composition revealed from Raman data with environmental parameters. Further environmental changes could be potentially tracked according to the otoliths spectral characteristics, provided that robust data sets are available. Understanding the effects of environmental factors on the chemical composition and structure of otoliths could be very useful in the field of fisheries science, biomineralization or sclerochronology. Their use in reconstructing fish migratory paths or in analyzing population structure could prove to be very important in future approaches.

\section{EXPERIMENTAL}

\section{Materials}

One otolith was randomly selected from a stock of 16 adults of gilthead sea bream, Sparus aurata, collected from four locations in the eastern Adriatic Sea during 2017 (open sea, coastal waters, estuary and aquaculture rearing cages). The studied otolith is from a female captured from estuary area of Novigrad - Karinsko Sea, (Zadar County, Croatia), weighting $274 \mathrm{~g}$ and $27 \mathrm{~cm}$ in length with an estimated age of 2.5 years. For standardization purposes, the left sagittae were systematically considered. The otoliths were washed in $30 \%$ hydrogen peroxide solution for 2-4 minutes and rinsed in distilled water. Samples were then cleaned in an ultrasonic bath (SONOREX SUPER RK $103 \mathrm{H}$ ) for 2 minutes and left to air-dry. Epoxy resin (MEGAPOXY H) was prepared by mixing three parts of resin and one part of hardener. These two components were stirred together for 2-3 minutes until the mixture changed color to translucent. The otoliths were embedded in the molds which were lightly coated with Struers Silicone and they were left to dry in the fume cupboard for one day.

Isomet low-speed diamond bladed saw was used for preparing otolith section. Saw was fitted with two blades separated by a spacer $(500 \mu \mathrm{m})$, producing a 400-500 $\mu \mathrm{m}$ otolith thin section. Each thin section was carefully grounded with Struers Labopol-5 using Struers wetted silicon carbide paper 
TRACKING THE GROWING RINGS IN BIOGENIC ARAGONITE FROM FISH OTOLITH USING CONFOCAL RAMAN MICROSPECTROSCOPY AND IMAGING

(4000 grit) at the speed of $50 \mathrm{rpm}$. Thin sections were then polished using a soft cloth sprayed with diamond paste $(3 \mu \mathrm{m})$ and washed again in ultrasonic bath for 2 minutes.

Stitched photography of otolith section has been achieved using a series of images taken with a ZEISS microscope equipped with AXIO camera and ZEN 2 (blue edition) program. Stitched image has been obtained with Image-Pro Premier 9.1 software. All sections (core and growth marks) were observed via optical microscopy. Opacity data were acquired on transects from the core to the ventral edge with black areas corresponded to opaque zones.

\section{Methods}

Confocal Raman spectra were acquired using a Renishaw InVia Confocal Raman System and a Cobolt DPSS laser emitting at $532 \mathrm{~nm}$. During Raman microscopy the, 5X (NA 0.12 WD $13.2 \mathrm{~mm}$ ), 20X (NA 0.35, WD $2 \mathrm{~mm}$ ) and 100X (NA 0.9, WD $3.4 \mathrm{~mm}$ ) collecting objectives were used with theoretical spatial resolutions of $2.7 \mu \mathrm{m}, 0.927 \mu \mathrm{m}$ and $0.36 \mu \mathrm{m}$ respectively, and for single spectra acquisitions at controlled distances from otolith core, the acquisition parameters were $1 \mathrm{~s}, 1$ acquisition, $200 \mathrm{mw}$ laser power. An edge filter has been employed to record spectra in the $90-1840 \mathrm{~cm}^{-1}$ spectral range with $0.5 \mathrm{~cm}^{-1}$ resolution. Signal has been detected using a Rencam CCD and data acquisition and processing has been achieved with WIRE 3.4 and Origin 8.1 software. Micrographs of the morphological details have been acquired along with spectral data acquisition using the video image facility of the WIRE software. Yearly growing rings have been observed via optical microscopy before Raman measurements and subtle incremental rings have been observed and mapped using the "signal-to-baseline" or "intensity-at-point" options of the Wire 3.4 mapping software.

\section{ACKNOWLEDGEMENT}

This work has been supported in part by Croatian Science Foundation under the project IP-2016-06-9884.

\section{REFERENCES}

1. S. E. Campana, Mar. Ecol. Prog. Ser., 1999, 188, 263-297.

2. S. E. Campana, S. R. Thorrold, Can. J. Fish. Aquat. Sci., 2001, 58(1), 30-38.

3. S. Cinta Pinzaru, S. Matić-Skoko, M. Peharda, D. Vrdoljak, H. Uvanović, C. Firta, G. Lazar, F. Nekvapil, L. Barbu-Tudoran, M. Suciu, B. Glamuzina, in Peharda, M., Ezgeta-Balić, D., Uvanović, H. (Eds). " $5^{\text {th }}$ Int. Sclerochronology Conf., 16-20 ${ }^{\text {th }}$ June 2019, Split, Croatia. Book of Abstracts", 2019, p. 144. 
GEZA LAZAR, CALIN FIRTA, SANJA MATIĆ-SKOKO, MELITA PEHARDA, DARIO VRDOLJAK, HANA UVANOVIĆ, FRAN NEKVAPIL, BRANKO GLAMUZINA, SIMONA CINTA PINZARU

4. R. P. Rodríguez Mendoza, Croat. J. Fish., 2006, 64 (3), 89- 102.

5. G. Behrens, L.T. Kuhn, R. Ubic, A. H. Heuer, Spectrosc. Lett., 1995, 28, 983-995.

6. S. E. Campana, Comp. Biochem. Physiol., 1983, 75A, 215-220.

7. R. W. Gauldie, J. Mar. Fish. Res.,1985, 20, 209-217.

8. J. M. Casselman, J. M. Gunn, Can. J. Fish. Aquat., Sci., 1992, 49(Supp1.1), 102111.

9. J. Tomás, A. J. Geffen, J. Fish Biol., 2003, 63(6), 1383-1401.

10. R. Brown, K. P. Severin, Can. J. Fish. Aquat. Sci., 1999, 56,1898-1903.

11. S. Melancon, B. J. Fryer, J. E Gagnon, S. A. Ludsin, and Z. Yang, Can. J. Fish. Aquat. Sci., 2005, 62, 2609-2619.

12. G. Nehrke, H. Poigner, D. Wilhelms-Dick, T. Brey, D. Abele, Geochem. Geophys. Geosyst., 2012, 13, Q05014.

13. R. W. Gauldie, S. K. Sharma, E. Volk, Comp. Biochem. Physiol. A-Physiol.,1997, 118, 753-757.

14. W. Kaabar, S. Bott, R. Devonshire, Spectrochim. Acta A Mol. Biomol. Spectrosc., 2011, 78,136-141.

15. N. Buzgar, Al. Apopei, An. Stiint Univ. Al. I. Cuza lasi, Geol., 2009, 55, 97-112.

16. U. Wehrmeister, A. L Soldati, D. E. Jacob, T. Häger, W. Hofmeister, J. Raman Spectrosc., 2010, 41, 193-201.

17. F. C. Donnelly, F. Purcell-Milton, V. Framont, O. Cleary, P. W. Dunne, Y. K. Gun'ko, Chem. Commun., 2017, 53, 6657-6660.

18. S. Farsang, S. Béclin, S. Redfern, Am. Min., 2018, 103, 1988-1998.

19. M. De La Pierre, C. Carteret, L. Maschio, E. André, R.Orlando, R. Dovesi, J. Chem. Phys., 2014, 140, 164509. 